\title{
Bibliometric analysis of Sri Lanka Journal of the Humanities
}

Navaneethakrishnan, $\mathrm{S}^{1}$ and Kupesan, $\mathrm{R}^{2}$

\begin{abstract}
This study especially focuses only on the articles published in the "Sri Lanka Journal of the Humanities" published by the University of Peradeniya. A total of 319 records of articles published in Sri Lanka Journal of the Humanities and authored by 147 authors during the period 1975 - 2009 (inclusive) were analyzed in this study. The objective of this study was to study bibliometric characteristics such as distribution of publications, research growth rate, and authorship pattern "Sri Lanka Journal of the Humanities". The research method of this study was Bibliometric analytical method. Findings of the analysis revealed that distributions of publications vary over the period of study and English occupies as dominant language. Research growth of publications was increased with positive indicators. Majority of the contributions were single authored. Author productivity varied between the observed percentage of authors and expected percentage of authors as predicted by applying Lotka's equation. Among the productive authors Peris, Merlin is in the top position with 26 contributions. In the ranked list of affiliated institutions, University of Peradeniya leads others. Zipf's Law was proportionally matching with the Frequency list of selected title words of this study.
\end{abstract}

Keywords: Bibliometrics, Sri Lanka, Humanities, Higher education

\section{Introduction}

Sri Lanka is one of the fast developing countries in South Asia. One of the key areas for the enhancement of development of Sri Lankan higher education sector is weighing and improving the research productivity and visibility of research publications of the Universities. In Sri Lanka few bibliometric studies have been done especially by some library professionals. This study especially focuses only on the articles published between the years 1975 -2009 (inclusive) in the "Sri Lanka Journal of the Humanities" published by the University of Peradeniya.

\footnotetext{
Corresponding author:

${ }^{1}$ Assistant Librarian, Main Library, University of Jaffna, Sri Lanka.Email:ksnavan@yahoo.com

${ }^{2}$ Assistant Librarian, Main Library, University of Jaffna, Sri Lanka.Email:kupeshan@ gmail.com
} 


\section{Introduction to Bibliometrics}

The studies on evaluation of academic productivity and quality have led to development of new academic fields such as Bibliometrics, Scientometrics and Informetrics. Etymologically, bibliometrics is derived from two Greek words, 'biblio' and 'metrikos' meaning book and measurement. Bibliometrics and librametry were commonly defined by Ravichandra Rao as "Information processes and information handling in libraries and information centres by quantitatively analyzing the characteristics and behavior of documents, library staff and library users" (Ravichandra Rao, 1981)

In 1917, the expression 'Statistical Analysis' has been used in a literature by Cole and Eales (1917) in their study. In 1923, a study was conducted by Hulme (1923), entitled 'Statistical Analysis of the History of Science'. His analysis was based on the entries in the English International Catalogue of Scientific Literature. A third study was the work of Gross and Gross (1927) reported in later. They counted and analyzed the citations in articles from the Journal of the American Chemical Society, and produced a list of journals deemed important to chemical education. Another prominent work was Bradford's 1934 article on the distribution of literature in lubrication research.

In 1948, S.R. Ranganathan, coined the term 'librametry', which historically appeared first and was intended to streamline the services of librarianship. Bibliometrics is analogous to Ranganathan's librametrics, the Russian concept scientometrics, infometrics, and sub disciplines like econometrics, psychometrics, sociometrics, biometrics, technometrics, chemometrics, and climetrics, where mathematics and statistics are applied to study and solve problems in the respective fields (Ranganathan, 1995).

The term 'bibliometrics' is preferred by Pritchard (1969) to replace the term 'statistical bibliography'; to mean the application of mathematics and statistical methods to books and other media of communication, which means bibliometrics is a sort of measuring technique by which inter-connected aspects of written communication can be quantified. 


\section{Sri Lanka Journal of the Humanities}

The Sri Lanka Journal of the Humanities is a bi-annual issue published by the University of Peradeniya, Sri Lanka. It is devoted to the publication of articles based on original research in the Humanities and the Social Sciences, which pertain mainly, though not exclusively, to Sri Lanka. It aims to publish a variety of scholarly and original articles on History, Archaeology, Philosophy, Literature, Language, Religion, the Arts and other related fields. 'Sri Lanka Journal of the Humanities' is one of the successors to the University of Ceylon Review (1943-67) and was known as the Ceylon Journal of the Humanities (1970-71) before assuming its present title. It is one of the few journals in the Sri Lankan University system to be published regularly over an extended period of time.

Furthermore, the journal is indexed in Bibliography of Asian Studies, International Bibliography of Periodical Literature, International Bibliography of Book Reviews of Scholarly Literature, MLA International Bibliography, and Directory of Periodicals. Articles are available in full text in the EBSCO database "Humanities International Complete" a database provided by EBSCO publishing (Perera, 2010).

\section{General objective}

- The objective of this study is to study bibliometric characteristics of the journal "Sri Lanka Journal of the Humanities".

\section{Specific objectives}

- To identify growth trend of publications with relevant indicators.

- To study authorship pattern of articles.

- To ascertain the author productivity with the comparison of Lotka"s Law

- To discover most prolific authors, affiliated institutions, and departments

- To recognize the relevance of Zipf's Law for the frequency distribution of title words 


\section{Statement of research problem}

Substantial amounts of funds are allocated for the higher educational institutions of a nation for research and development activities. It is a pressing need of a University to evaluate the research and development activities to ensure the validity, reliability, and the cost effectiveness of the research output. Lack of authoritative and quality information and data related to the trend of research and development is an obstacle to be resolved through only by analysis of research output or bibliometric studies. Basically bibliometric characteristics of research output are used to take correct decisions at institutional and national, regional, and international levels.

When the current trend of research output in articles of "Sri Lanka Journal of the Humanities" is identified, it makes sense to propose changes and suggest new developments. Therefore there is a demand for research on bibliometric characteristics of Sri Lanka Journal of the Humanities with particular reference to what are the characteristics and contributions of research articles published in the Sri Lanka Journal of the Humanities and how these contributions pave the way for bibliographic growth is identified as main problem of this study.

\section{Review of Literature}

Analysis of existing literature reveals that even variety of bibliometric research studies done to date, the amount of investigation on the humanities and social sciences and their disciplines is considerably smaller than in science and technology. Historically, bibliometric studies have fallen, initially at least, into two broad categories. In the first category are those studies that evaluate and often assess the suitability of the tools and theories used in bibliometrics. The second category is those studies which use bibliometric methods in order to describe, explain, predict, and evaluate the communication behavior of scholars (Borgman \& Furner, 2002).

This kind of bibliometric studies could be focused on a particular communication form or media like journal, conference proceedings, and e-journal. These studies are conducted to 
find out key bibliometric components of publication output in an individual form of communication. Similar bibliometric analysis were undertaken by Schrader (1985); Schrader and Beswick (1989); Stephenson (1993); Ramesh and Nagaraju (2002); Senthilkumaran and Vadivel (2004); Kaur (2006); Biswas, Roy and Sen (2007); Jennings, Ehrhardt and Poling (2008); Thelen (2010); Narang and Anil Kumar (2010); Thanuskodi (2011); and Lin and Jeong-Yeou Chi (2012).

The existing literature analysis also reveals that only a few number of research studies were carried in Sri Lanka. Weerasooriya (1999) conducted a study on the application of mathematics and statistics into the area of library and information science, its significance and uses. Yapa, De Silva and De Silva (2004) conducted a bibliometric analysis of institutional research productivity in nine Sri Lankan research laboratories in the field of natural products chemistry. Maheswaran (2007) evaluated the usefulness of bibilometric application for the analysis of Sri Lankan Tamil publications in the year 2005.

Bibliometric study was conducted by Gunasekera (2008) on LIS research literature of Sri Lanka over 141 articles from the two LIS journals for the period from 1997 to 2007. Wickremasinghe (2008) conducted a research to identify the research productivity of rice scientists in India and Sri Lanka through their publications and other research outputs. Wickremasinghe and Srikumaran (2009) examined the strengths of Research and dynamics of Sri Lanka based on the research publications of the journal of the NSF. A Bibliometric Study was conducted by Perera (2011) on WHO Publications, available in the Medical library, University of Peradeniya with the objective of making the readership and the library staff awareness of what is available in the collection. Pratheepan (2011) conducted a scientometric study to analyse the scientific performance of the University of Ruhuna during 1999-2010 in terms of scientometric indicators by using ISI WoS database. Gupta (2012) assessed the science and technology research output of Sri Lanka during 20012010. Navaneethakrishnan (2013) identified the trends in Sri Lankan research performance as reflected by the research publications output between years 1980-2009 based on scientific publications included in the SciVerse Scopus database. Dambawinna (2013) 
conducted a citation analysis of the Ceylon Journal of Science published by University of Peradeniya, Sri Lanka. Angammana, (2013) studied 4901 citations extracted from 70 theses submitted to University of Colombo and University of Kelaniya during the period 1999 to 2009 to identify the bibliometric features.

The present study could enable to bridge the research gap on bibliometrics studies focused on particular journal in Sri Lanka by analyzing the bibliometric features of the Sri Lanka Journal of the Humanities.

\section{Methodology}

The research method of this study was Bibliometric analytical method that adopts detailed analysis of secondary data using a range of bibliometric laws and scientometric tools, techniques and formulas along with statistical techniques. A total of 319 records of articles published in Sri Lanka Journal of the Humanities published by University of Peradeniya and authored by 147 authors during the period 1975 - 2009 (inclusive) were analyzed in this study. In the study each individual article was scanned, checked, examined and tabulated for necessary data in to separate sheets and analyzed using Ms excel and Bibexcel software developed by Olle person. (Persson, O, Danell, R, \& Wiborg Schneider, J, 2009).

Chronological distributions of publications were presented in the tables. Analysis of research trend and growth of publications was carried out by calculating the, accumulated growth and average. Authorship patterns were identified by distribution of co-authorship. Author productivity based on number of publications was identified and checked with Lotka's Law. Most prolific authors and affiliated institutions and departments were identified. Distribution of words was analyzed by applying Zipf's Law on words in article titles. 


\section{Data Analysis and Findings}

\section{Year- wise distribution of research Publications}

The analysis of chronological distribution of publications of the total records reveals that, out of 319 publications published during the period 1975 - 2009, maximum numbers of 21were published in 1992 followed by 1990 with 17. Minimum numbers of 5 and 6 articles were published during the years of 1980 and 2000 respectively. (Fig 8.1)

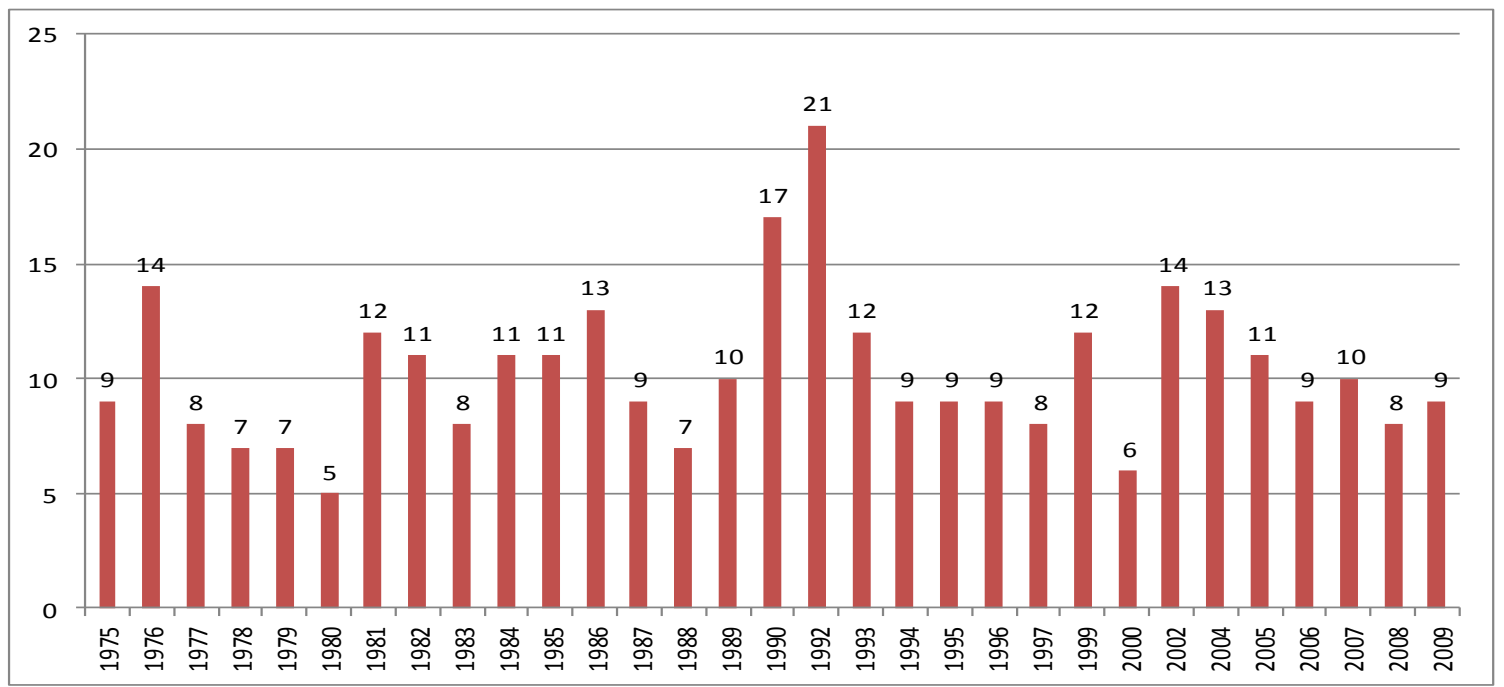

Fig 8.1- Chronological distribution of publications

\section{Analysis of growth of publications}

While analyzing the growth trend of publications, it is observed that the range of number of articles published per year during the period under study is in between 5-21. It is also observed that approximately 50\% of entire publications output brought from 1975 to1990 and the balance (50\%) were published between 1992 and 2009. Even though cumulative total increased over the years cumulative average fluctuated during the study period. (Table 8.1) 
Journal of the University Librarians Association of Sri Lanka, Vol.18, Issue 1, January 2014

Table 8.1 Chronological distribution of publications

\begin{tabular}{|c|c|c|c|c|c|}
\hline Year & $\begin{array}{l}\text { No. of } \\
\text { Articles }\end{array}$ & Percentage & $\begin{array}{l}\text { Cumulative } \\
\text { total }\end{array}$ & $\begin{array}{l}\text { Cumulative } \\
\text { percentage }\end{array}$ & $\begin{array}{l}\text { Cumulative } \\
\text { average }\end{array}$ \\
\hline 1975 & 9 & 2.8 & 9 & 2.8 & 9.0 \\
\hline 1976 & 14 & 4.4 & 23 & 7.2 & 11.5 \\
\hline 1977 & 8 & 2.5 & 31 & 9.7 & 10.3 \\
\hline 1978 & 7 & 2.2 & 38 & 11.9 & 9.5 \\
\hline 1979 & 7 & 2.2 & 45 & 14.1 & 9.0 \\
\hline 1980 & 5 & 1.6 & 50 & 15.7 & 8.3 \\
\hline 1981 & 12 & 3.8 & 62 & 19.4 & 8.9 \\
\hline 1982 & 11 & 3.4 & 73 & 22.9 & 9.1 \\
\hline 1983 & 8 & 2.5 & 81 & 25.4 & 9.0 \\
\hline 1984 & 11 & 3.4 & 92 & 28.8 & 9.2 \\
\hline 1985 & 11 & 3.4 & 103 & 32.3 & 9.4 \\
\hline 1986 & 13 & 4.1 & 116 & 36.4 & 9.7 \\
\hline 1987 & 9 & 2.8 & 125 & 39.2 & 9.6 \\
\hline 1988 & 7 & 2.2 & 132 & 41.4 & 9.4 \\
\hline 1989 & 10 & 3.1 & 142 & 44.5 & 9.5 \\
\hline 1990 & 17 & 5.3 & 159 & 49.8 & 9.9 \\
\hline 1992 & 21 & 6.6 & 180 & 56.4 & 10.6 \\
\hline 1993 & 12 & 3.8 & 192 & 60.2 & 10.7 \\
\hline 1994 & 9 & 2.8 & 201 & 63.0 & 10.6 \\
\hline 1995 & 9 & 2.8 & 210 & 65.8 & 10.5 \\
\hline 1996 & 9 & 2.8 & 219 & 68.7 & 10.4 \\
\hline 1997 & 8 & 2.5 & 227 & 71.2 & 10.3 \\
\hline 1999 & 12 & 3.8 & 239 & 74.9 & 10.4 \\
\hline 2000 & 6 & 1.9 & 245 & 76.8 & 10.2 \\
\hline 2002 & 14 & 4.4 & 259 & 81.2 & 10.4 \\
\hline 2004 & 13 & 4.1 & 272 & 85.3 & 10.5 \\
\hline 2005 & 11 & 3.4 & 283 & 88.7 & 10.5 \\
\hline 2006 & 9 & 2.8 & 292 & 91.5 & 10.4 \\
\hline 2007 & 10 & 3.1 & 302 & 94.7 & 10.4 \\
\hline 2008 & 8 & 2.5 & 310 & 97.2 & 10.3 \\
\hline 2009 & 9 & 2.8 & 319 & 100.0 & 10.3 \\
\hline
\end{tabular}




\section{Analysis of authorship pattern}

Fig 8.2 shows the authorship pattern of publications. It could be noted that single authored papers rank first with having $98.1 \%$. The next place is recorded by two authored papers having $1.6 \%$ of the total research contributions. Three authored contributions take the third position that occupying $0.3 \%$ of the total publication. It indicates that the multi authored work is extremely less than that of the single authored contributions.

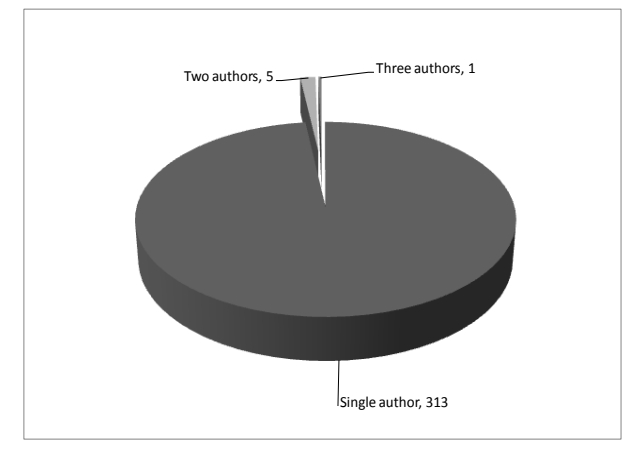

Fig. 8.2 - Distribution of authorship pattern

In general majority of the early publications are contributed by single author and multi authored work was appeared since 1981. Range of number of authors was one to three and the highest number of collaborative authors for a single publication was observed in the year 2002 with three authors. (Table 8.2)

Table 8.2: Chronological display of authorship patterns

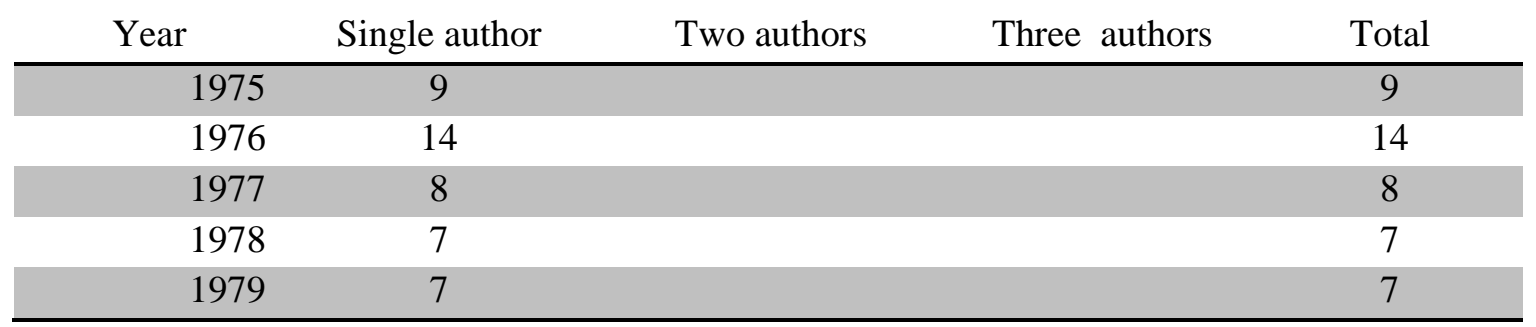




\begin{tabular}{|c|c|c|c|c|}
\hline 1980 & 5 & & & 5 \\
\hline 1981 & 11 & 1 & & 12 \\
\hline 1982 & 11 & & & 11 \\
\hline 1983 & 7 & 1 & & 8 \\
\hline 1984 & 11 & & & 11 \\
\hline 1985 & 11 & & & 11 \\
\hline 1986 & 13 & & & 13 \\
\hline 1987 & 9 & & & 9 \\
\hline 1988 & 7 & & & 7 \\
\hline 1989 & 10 & & & 10 \\
\hline 1990 & 17 & & & 17 \\
\hline 1992 & 21 & & & 21 \\
\hline 1993 & 12 & & & 12 \\
\hline 1994 & 9 & & & 9 \\
\hline 1995 & 9 & & & 9 \\
\hline 1996 & 8 & 1 & & 9 \\
\hline 1997 & 8 & & & 8 \\
\hline 1999 & 12 & & & 12 \\
\hline 2000 & 6 & & & 6 \\
\hline 2002 & 13 & & 1 & 14 \\
\hline 2004 & 12 & 1 & & 13 \\
\hline 2005 & 11 & & & 11 \\
\hline 2006 & 8 & 1 & & 9 \\
\hline 2007 & 10 & & & 10 \\
\hline 2008 & 8 & & & 8 \\
\hline 2009 & 9 & & & 9 \\
\hline Total & 313 & 5 & 1 & 319 \\
\hline
\end{tabular}

\section{Analysis of author productivity}

The Lotka's law is applied to find out author productivity and it is presented in Table 8.3. From the table it is evident that the observed percentage of authors slightly varied from the expected percentage of authors as predicted by applying Lotka's equation. Although the author productivity results were not exactly match with the Lotka's law, approximately it matches with the Lotka's law. 
Journal of the University Librarians Association of Sri Lanka, Vol.18, Issue 1, January 2014

Table 8.3 : Lotka's Law on author productivity

\begin{tabular}{ccccc}
\hline $\begin{array}{c}\text { No. of articles } \\
\text { published }\end{array}$ & $\begin{array}{c}\text { Observed } \\
\text { No. of Authors } \\
\left(\mathrm{a}_{\mathrm{n}}\right)\end{array}$ & $\begin{array}{c}\text { Observed } \\
\text { \% of authors } \\
100 * \mathrm{a}_{\mathrm{n}} / \mathrm{a}_{1}\end{array}$ & $\begin{array}{c}\text { Expected } \\
\text { no. of authors } \\
\mathrm{a}_{\mathrm{n}}=\mathrm{a}_{1} / \mathrm{n}^{2}\end{array}$ & $\begin{array}{c}\text { Expected \% of } \\
\text { author predicted by } \\
\text { Lotka }\left(100 / \mathrm{n}^{2}\right)\end{array}$ \\
\hline 1 & 96 & 65.31 & 96 & 63.93 \\
2 & 20 & 13.61 & 24 & 15.98 \\
3 & 9 & 6.12 & 11 & 7.10 \\
4 & 9 & 6.12 & 6 & 4.00 \\
5 & 4 & 2.72 & 4 & 2.56 \\
6 & 1 & 0.68 & 3 & 1.78 \\
7 & 1 & 0.68 & 2 & 0.79 \\
9 & 2 & 1.36 & 1 & 0.64 \\
10 & 1 & 0.68 & 1 & 0.64 \\
12 & 2 & 1.36 & 1 & 0.64 \\
16 & 1 & 0.68 & 1 & 0.64 \\
26 & 1 & 0.68 & 1 & 100.00 \\
\hline
\end{tabular}

\section{Most prolific authors based on number of publications}

In order to indentify the productive authors, individual authors were ranked in terms of their productivity based on number of publications over the years. Among the productive authors Peris, Merlin attached to the Department of Western Classics, University of Peradeniya, Sri Lanka is in the top position with 26 publications. Weerakkody, D.P.M. attached to the Department of History, University of Peradeniya was in the second rank with 16 publications followed by Gunawardana, R.A.L.H. Department of History of the University of Ceylon with 12 publications. (Table 8.4) 
Journal of the University Librarians Association of Sri Lanka, Vol.18, Issue 1, January 2014

Table 8.4 :Most productive authors based on number of publications

\begin{tabular}{|c|c|c|c|c|c|c|c|c|c|c|c|c|c|}
\hline Author & 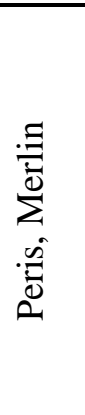 & 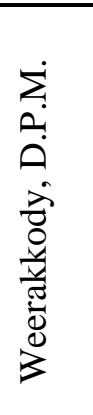 & 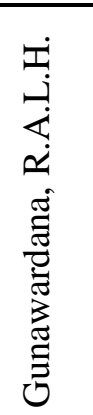 & 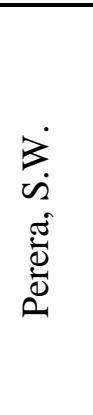 & 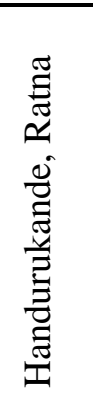 & 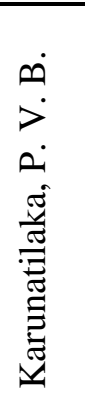 & 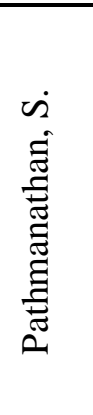 & 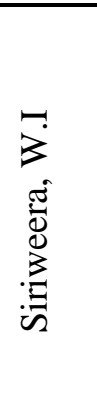 & 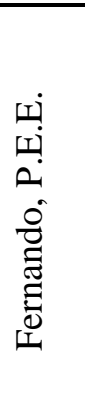 & 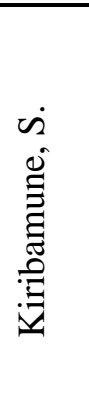 & 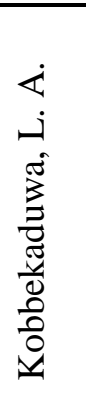 & 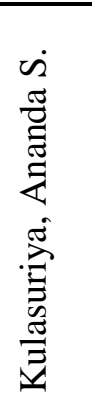 & 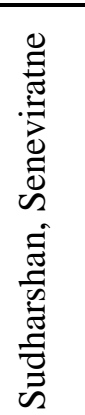 \\
\hline Total & 26 & 16 & 12 & 12 & $\overline{10}$ & $\overline{9}$ & 9 & 7 & 6 & 5 & 5 & 5 & 5 \\
\hline Percentage & $8 \%$ & $5 \%$ & $4 \%$ & $4 \%$ & $3 \%$ & $3 \%$ & $3 \%$ & $2 \%$ & $2 \%$ & $2 \%$ & $2 \%$ & $2 \%$ & $2 \%$ \\
\hline 1975 & & & 1 & & & & & & 1 & & & & \\
\hline 1976 & 1 & & 1 & & & & 1 & & 1 & & & & \\
\hline 1977 & 1 & & & & & & & & & 1 & & & \\
\hline 1978 & 1 & & 1 & & & & & & 1 & & & & \\
\hline 1979 & & & 1 & & & & 1 & & & 2 & & & \\
\hline 1980 & & & & & 1 & 1 & & & & & & & \\
\hline 1981 & 1 & 1 & 2 & & & & & & 1 & 1 & & & \\
\hline 1982 & 1 & & 1 & & 2 & & 1 & & 1 & & & & \\
\hline 1983 & 1 & & & & & 1 & & 1 & 1 & & & & \\
\hline 1984 & 1 & 1 & 1 & & 1 & & 1 & & & & & & \\
\hline 1985 & 2 & 1 & 1 & & 1 & & & & & & & & 1 \\
\hline 1986 & 1 & & & & 1 & & & 1 & & & & & 1 \\
\hline 1987 & 1 & 1 & & & & 2 & & & & & & & \\
\hline 1988 & 1 & 1 & 1 & & & 1 & & & & & & 1 & \\
\hline 1989 & 1 & 2 & & & & 1 & & 1 & & & & & 1 \\
\hline 1990 & 1 & 2 & 1 & 1 & 1 & 1 & & & & & 1 & 1 & \\
\hline 1992 & 1 & 2 & & 1 & 1 & 1 & & 1 & & 1 & 1 & 2 & \\
\hline 1993 & 1 & 1 & & 1 & 1 & & 1 & 1 & & & & & 1 \\
\hline 1994 & 1 & 1 & & 1 & & & 1 & & & & 1 & & \\
\hline 1995 & 1 & 2 & & 1 & & 1 & 1 & & & & 1 & & 1 \\
\hline 1996 & 1 & & & 1 & & & & & & & 1 & & \\
\hline 1997 & 1 & & & 1 & & & 1 & & & & & & \\
\hline 1999 & 1 & & & 1 & 1 & & 1 & & & & & & \\
\hline 2000 & & & & 1 & & & & & & & & & \\
\hline 2002 & 1 & & 1 & & & & & & & & & 1 & \\
\hline
\end{tabular}




\begin{tabular}{lllll}
\hline 2004 & 1 & 1 & 1 & 1 \\
2005 & 1 & & 1 & 1 \\
2006 & 1 & & 1 & \\
2007 & & & & \\
2008 & 1 & & & \\
2009 & & & & \\
\hline
\end{tabular}

\section{Most prolific affiliated institutions}

A rank list of affiliated institution of the contributors has been prepared based on the number of contributions from respective institutions, campuses and universities. Table 8.5 depicts the distribution of affiliated institutions and universities, which produced more than 2 contributions. It can be observed that the University of Peradeniya leads with having 200 contributions followed by University of Sri Jeyawardenepura and University of Colombo.

Table 8.5 - Ranked list of most productive institutions

\begin{tabular}{lc}
\hline Name of the Affiliated institution & No. of publications \\
\hline University of Peradeniya & 190 \\
Peradeniya Campus of University of Sri Lanka & 20 \\
University of Sri Jayewardenepura & 6 \\
University of Colombo & 5 \\
University of Ceylon & 5 \\
Vidyalankara Campus of the University of Sri Lanka & 5 \\
Whitman College & 4 \\
University of Kelaniya & 3 \\
National Museum Kandy & 3 \\
University of Ruhuna & 3 \\
Cambridge University & 3 \\
University of South Carolina & 3 \\
\hline
\end{tabular}

\section{Most prolific departments}

The individual departments of the universities play a vital role in the development of research and publications of the respective universities. Measuring the contributions of 
these departments individually could be contributed to not only find out the prolific departments but also to encourage the departments to increase their publications which have law rate. A rank list of affiliated departments of the contributors has been prepared based on the number of contributions from respective departments. Table (8.6) depicts the distribution of affiliated departments, which produced more than 4 contributions. Among the whole 319 publications, it can be observed that the top five departments are Department of History, Department of Western Classics, Department of English, Department of Sinhala and Department of Sanskrit, University of Peradeniya.

Table 8.6 - Ranked list of most productive departments

Name of the Department

No. of publications

Department of History, University of Peradeniya. 45

Department of Western Classics, University of Peradeniya. 42

Department of English, University of Peradeniya.

Department of Sinhala, University of Peradeniya. 19

Department of Sanskrit, University of Peradeniya. 16

Department of Philosophy, University of Peradeniya. 12

Department of Archaeology, University of Peradeniya.

Department of Education, University of Peradeniya. 5

Department of Economics, University of Peradeniya. 4

Department of English, University of Colombo.

4 


\section{Application of Zipf's Law on words in article titles}

Zipf's Law states that in a relatively lengthy text, if the words occurring within that text are listed in order of decreasing frequency, the rank of a word on that list multiplied by its frequency will equal a constant. The equation for this relationship is: $\mathrm{rx} \mathrm{f}=\mathrm{k}$ where $\mathrm{r}$ is the rank of the word, $\mathrm{f}$ is the frequency, and $\mathrm{k}$ is the constant Kromer, V (2002). Accordingly the title fields of the articles were taken for this analysis and tested whether the frequency of any word is inversely proportional to its rank in the frequency table. (Table 8.7) While considering the words with more than 8 in frequency, it is found that rank and frequency of words are not always relative and multiplication of them is not equal to a constant. Zipf's law is not match with the findings.

Table 8.7 -Frequency list of words in title and relevance to Zipf's Law

\begin{tabular}{|c|c|c|c|}
\hline Rank ( r) & Word & Frequencies (f) & $\begin{array}{c}\text { Multiplication of } r \& f \\
r \times f=k \text { (expected constant) }\end{array}$ \\
\hline 1 & Sri Lanka & 74 & 74 \\
\hline 2 & Early & 19 & 38 \\
\hline 3 & Ancient & 18 & 54 \\
\hline 4 & Sinhala & 15 & 60 \\
\hline 5 & Buddhism & 13 & 65 \\
\hline 6 & History & 12 & 72 \\
\hline 7 & Buddhist & 12 & 84 \\
\hline 8 & Study & 11 & 88 \\
\hline 9 & Education & 11 & 99 \\
\hline 10 & Lankan & 11 & 110 \\
\hline 11 & Review & 11 & 121 \\
\hline 12 & Tamil & 10 & 120 \\
\hline 13 & India & 10 & 130 \\
\hline
\end{tabular}


Journal of the University Librarians Association of Sri Lanka, Vol.18, Issue 1, January 2014

\begin{tabular}{llll}
\hline 14 & Greek & 10 & 140 \\
15 & Literature & 10 & 150 \\
16 & Century & 10 & 160 \\
17 & Women & 9 & 153 \\
18 & Medieval & 9 & 162 \\
19 & Sinhalese & 9 & 171 \\
20 & English & 8 & 160 \\
\hline
\end{tabular}

\section{Distribution of publications based on Length}

Findings derived from the analysis of number of pages per article, which is a dimension with potentially more significant meaning, shows that majority of articles (176) have pagination length below 15. 41articles have pagination length of more than 30 pages.(Fig 8.3)

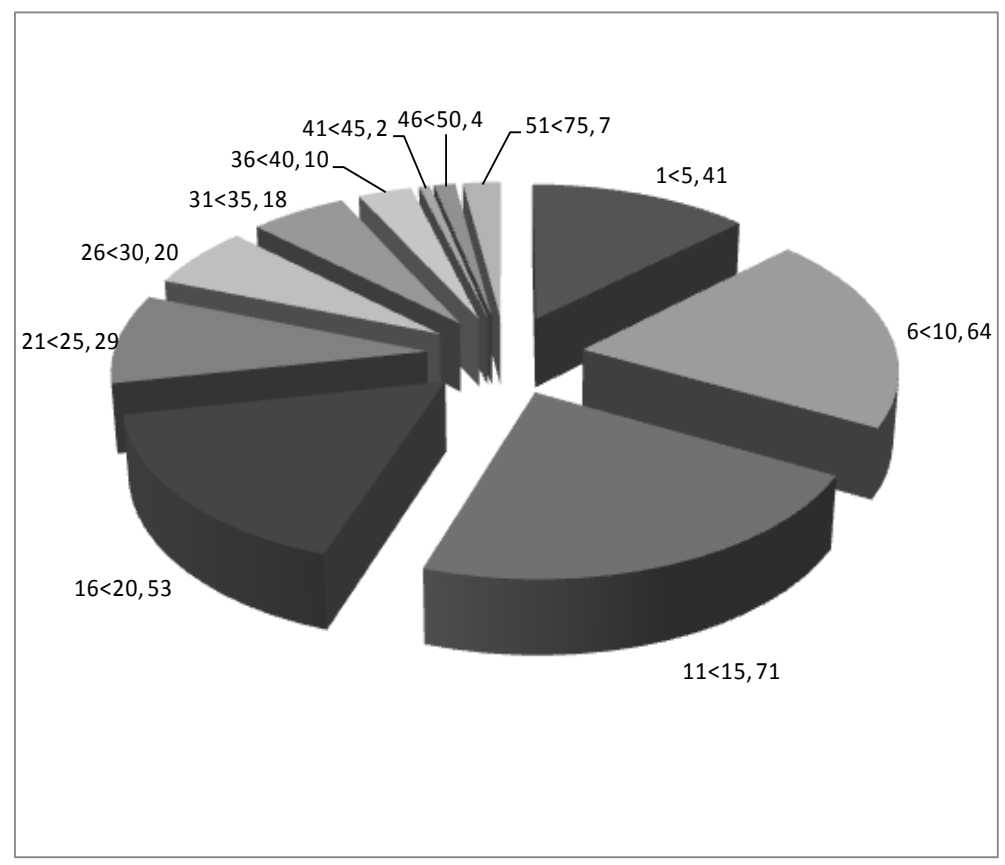

Fig.8.3 - Distribution of length of publication. 


\section{Conclusion}

Findings of the analysis reveal that distributions of publications vary over the period of study and English occupies as dominant language. Research growth of publications is increased with positive indicators. Majority of the contributions are single authored. Author productivity varied between the observed percentage and expected percentage of authors as predicted by Lotka"s Law. Among the most productive authors Peris, Merlin attached to the Department of Western Classics, University of Peradeniya, Sri Lanka is in the top position with 26 contributions. In the ranked list of affiliated Institutions, University of Peradeniya leads others. Zipf's law is proportionally matching with the frequency list of selected title words of this study.

\section{Suggestions}

When the findings explored through an analysis it resulted to suggestions and subject areas for further research. Following were suggested according to the findings of this study.

- Sri Lanka Journal of the Humanities should encourage the academic community to increase their research activities to maintain the steady growth of publication.

- Foreign contributions could be encouraged to popularize and recognize the Sri Lanka Journal of the Humanities at international level.

- Sri Lanka Journal of the Humanities has to maintain the continuity of publication range without dropdown over the years.

- Contributions from the Departments other than History and Languages should be increased to maintain the subject balance of the journal.

- More and more interdisciplinary and multidisciplinary nature of new research activities could be encouraged to maintain and increase the degree of collaboration.

- Policy decision also should be taken by the relevant administrative and editorial bodies to improve the visibility of research publications of this journal.

- Research can be undertaken to identify the bibliometric characteristics of research output of other individual journals in Sri Lanka. 


\section{References}

Angammana, A.M.S. (2013). A Bibliometric study of postgraduate theses in Library and Information Science: with special reference to University of Kelaniya and University of Colombo. Co-word analysis of literature on information retrieval. Unpublished MSSC thesis, University of Kelaniya.

Biswas, B. C., Roy, A. and Sen, B. K. (2007). Economic botany - a bibliometric study. Malaysian Journal of Library \& Information Science, 12(1), 23-33.

Borgman, C.L., \& Furner, J. (2002). Scholarly Communication and Bibliometrics. In B. Cronin (Ed.), Annual Review of Information Science and Technology, Vol 36. Medford, NJ: Information Today, 3-72.

Cole, F. J. and Eales, N. B. (1917) .The history of comparative anatomy part I: - a statistical analysis of literature science. Science Progress, 11, 578-596.

Dambawinna, K. P. K. (2013). Citation Analysis of Ceylon Journal of Science (Biological Sciences) In: 6th Annual Research Conference of the Royal Asiatic Society of Sri Lanka, March 28th, 29th and 30th 2013, Sri Lanka.

Gross, P. L. K. and Gross, F. M. (1927). College Libraries and Chemical Education. Science, 66,386-389.

Gunasekera,C. (2008). Library and Information Sciences Research Literature in Sri Lanka: A bibliometric Study. Journal of the University Librarians Association of Sri Lanka, 12, 17-46.

Gupta, B. M. et al.. (2002). Comparative profile of S\&T research in India and China a quantitative analysis of publication output DESIDOC Bulletin of Information Technology, 22 (1),21-32.

Hulme, E.W. (1923). Statistical bibliography in relation to the growth of modern Civilization, London: Grafton.

Jennings, R. L. Ehrhardt, K. and Poling, A. (2008). A Bibliometric Analysis of School Psychology International 1995-2007 . School Psychology International, 29 (5),515528. 
Kaur, H. (2006) .Bibliometric Study of Malayan Law Journal Articles. Legal Information Management, 6 (1), 49-54.

Kromer, V. (2002). Zipf's law and its modification possibilities. Glottometrics 5, 1-13.

Lin, W. C. and Jeong, Y. C. (2012). A Bibliometric Study of the Journal of Educational Media \& Library Sciences: 1970-2010. Journal of Educational Media \& Library Sciences, 49 (3), 309-313.

Maheswaran, R. (2007). Bibliometric phenomenon of Tamil Publications in Sri Lanka in 2005. Journal of the University Librarians Association of Sri Lanka, 11,2-36.

Narang, A. and Kumar, A. (2010). A bibliometric study of Indian Journal of pure and applied Mathematics. SRELS Journal of Information Management, 47 (1),31-40.

Navaneethakrishnan, S. (2013). Sri Lankan research output at international level - A Picture from SCOPUS In: P Ranasinghe ed. International Conference on Social Sciences Sri Lanka -2013 (ICSS) 22-23 November 2013, Kelaniya:University of Kelaniya, 42-42.

Perera, S. (2011) .a Bibliometric Study on W H O Publications Available in the Peradeniya Medical Library In: Proceedings of the Peradeniya University Research Sessions Vol 16, 24th November 2011, Sri Lanka, Peradeniya: University of Peradeniya,7.

Perera, S.W. (2010). In editorial note appeared in the cover page of the Sri Lanka Journal of the Humanities, $36(1,2)$ unnumbered.

Persson, O, Danell, R. \&Wiborg Schneider, J .(2009) .How to use Bibexcel for various types of bibliometric analysis In: F Åström, R Danell,B Larsen, \& J Wiborg Schneider Eds, Celebrating scholarly communication studies: A festschrift for Olle Persson at his 60th birthday Vol 5, pp 9-24) Leuven, Belgium: International Society for Scientometrics and Informetrics.

Pratheepan, T. (2011). Scientific Performance of the University of Ruhuna During 19992010 Based on the ISI WoS Database: A Scientometric Study Proceeding of International Symposium, Faculty of Agriculture, University of Ruhuna, 09, November, 2011.

Pritchard, A. (1969). Statistical bibliography or bibliometric?. Journal of Documentation .25 (4), 348-349. 
Ramesh, L S R C V; Nagaraju, A V S S (2002) Publication pattern in 'International Journal of Tropical Agriculture,' 1991-2000 a bibliometric study. SRELS Journal of Information Management ,39 (4) ,457-465.

Ranganathan, S.R. (1995) Librametry and its scope [reprinted]. The International Journal of Scientometrics and Informetics, 1(1) March 1995,15-21.

Ravichandra Rao, I. K .(1981). Bibliometrics: Its theory and practice In: G Battacharyya ed DRTC Refresher seminar -13 (1981), 14-17 October 1981, Bangalore Bangalore: Documentation research and training centre.

Schrader, A. and Beswick, L. (1989). The first five years of PLQ, 1979-1984 a bibliometric analysis. Public Library Quarterly, 9 (2) ,3-23.

Schrader, A. M. (1985) .A bibliometric study of the JEL, 1960-1984.) Journal of Education for Librarianship, 25 (4) , 279-300.

Senthilkumaran, P and Vadivel, V (2004) Journal of Spices and aromatic crops - a bibliometric appraisal. SRELS Journal of Information Management,41(1) 121131.

Stephenson, M. S. (1993). The Canadian Library Journal, 1981-91: an analysis. Canadian Journal of Information Science, 18 (2),1-18.

Thanuskodi, S. (2011). Bibliometric Analysis of the Indian Journal of Chemistry. Library Philosophy and Practice (International) July, 2011,1-7.Retreiveed from : http://www.digitalcommons.unl.edu/libphilprac/630.

Thelen, M. (2010). A Bibliometric Study of the Journal of Humanistic Psychology. Unpublished Ph.D. Thesis, Faculty of the Colorado School of Professional Psychology .

Weerasooriya, W.A. (1999). Application of mathematics and statistics into the curriculums of library and information science, its significance and uses and some ideas on bibliomatrics. Sri Lanka Library Review, 13 (1/2), 25-32.

Wickremasinghe S. I. (2008). Evaluating Research Productivity: A case study of the rice scientists in India and Sri Lanka. Journal of National Science Foundation, a, 36(1), 59-60. 
Wickremasinghe, S. I. and Srikumaran, N. (2009). Mapping local science and technology research: a profile based on the Journal of National Science Foundation of Sri lanka In: Sri Lanka Association of the Advancement of Science Proceedings of the 65th Annual sessions, 2009, Sri Lanka. Sri Lanka: Sri Lanka Association of the Advancement of Science, 173.

Yapa, G, De Silva, M.A.T.,De Silva, E. D. (2004). Trends and shifts in institutional productivity natural products chemistry research in Sri Lanka. Research Evaluation, 13 (3),167-174. 